\title{
Review
}

\section{More Shades of Grey Than Black and White: A Brief Review of Management of Anorectal Fistula}

SeneviratneRW ${ }^{1}$, KumaraMMJK1, De Silva PV ${ }^{1}$

${ }^{1}$ Faculty of Medicine, University of Ruhuna, Sri Lanka

\begin{abstract}
Search for ideal treatment of perianal fistula which will fulfill the objectives of low recurrence rate, minimal incontinence and good quality of life continues. Widely used methods for declination of fistula is include examination under anesthesia (EUA), endoanal ultrasound (EUS) and MRI, which is the gold standard. Wide range of procedures have been developed from simple ones such as loose seton to sphincter saving fistula plugs ending with extreme options such as temporary or permanent fecal diversion. Innovative therapeutic techniques such as the use of laser and adipose stem cells have shown some successes but require more advancements and improvements before been accepted in to wider practice.

While simple fistulas can be managed without much difficulty options for complex ones need careful selection. Sphincter saving options are widely preferred. Success of Ligation of intersphincteric fistula tract (LIFT) appears to be popular. Endorectal advancement flap (ERAF) is accepted by many as the Gold standard for treatment of recurrent complex anal fistula. Many surgeons judiciously combine different techniques employing them sequentially or simultaneously to enhance success rate and mitigate disadvantages. Repeated operations are performed without much hesitation provided they are sphincter saving as healing can arrive at any stage of the disease. Management of fistulas associated with Crohn's disease is a particularly complex entity requiring multidisciplinary involvement and multimodality treatment.

Research continues seeking more successful options but it appears unlikely that given the variability in presentation and complexity of the disease a single successful method of treatment will ever be found for management of perianal fistula.
\end{abstract}

Key words: Perianal fistula, perianal abscess, recurrent fistula, fistula plug

Copyright: (C) 2017 Seneviratne RW et al. This is an open access article distributed under the Creative Commons Attribution License, which permits unrestricted use, distribution, and reproduction in any medium, provided the original work is properly cited.

Funding: None

Competing interest: None

$\square$ Correspondence: ranjanamst@yahoo.com

DOI: http://doi.org/10.4038/amj.v11i1.7609

\section{Introduction}

Anorectal fistula described initially by Hippocrates continues to plague surgeons and patients alike since the dawn of civilization. Although true prevalence is unknown due to distracting presence of more common hemorrhoids, it is at least twice common in men as a result of higher density of perianal glands. Almost third of the perianal abscesses develop fistula and those growing Escherichia coli and Bacteroids have a higher chance for an associated fistula than the ones growing staphylococci (1).
It can be considered a chronic phase in anorectal sepsis characterized by ongoing discharge, intermittent pain and abscess formation which may discharge spontaneously(2). More than $90 \%$ of fistulas are caused by crypto-glandular infection, thus their internal openings are always at the level of pectinate line (1)(2). However, sepsis may spread up and secondary openings caused by spontaneous discharge or surgery may potentially occur anywhere (1). Although rare to produce fatal complications, quality of life of patients are seriously affected by frequent smelly 
discharges, poor healing, recurrent septic episodes and repeated surgeries.

Adherence to standard principles of the management of any fistula such as control of sepsis, care of nutritional status, delineation of anatomy and performing appropriate surgical procedures (SNAP) is vital for effective management of this troublesome disease. The range of treatment modalities is increasing and many a research has been directed a clear indication of the absence of proven effective management strategy. Main objectives of all of them are to eradicate sepsis, promote healing, minimize recurrence and ensure good quality of life(2). Simple low fistulas are often managed successfully by simply laying open with very high rate of success. However, surgery on complex ones could incur serious and permanent damage to sphincter mechanism inviting incontinence due to intertwining anatomical relationship between fistular tract and sphincter mechanism. This has led to popularization of sphincter saving options such as fistula plug and Ligation of intersphincteric fistular tract (LIFT).

Many surgeons categorize fistulas with following features as complex (3): Traverse more than $30 \%$ of external sphincter, Recurrent fistulas, Fistulas with branching tracts, Anterior fistulas associated with previous obstetric injury in women, Pre-existing incontinence, Local irradiation and Pre-existing Crohn's disease.

\section{Assessment of the fistula}

Accurate preoperative anatomical assessment is of clear benefit in complex fistulas although examination under anesthesia (EUA) and intraoperative assessment usually suffice in simple fistulas. Even some complex ones can be delineated by good clinical examination, sometimes under anesthesia with the help of simple tools such as fistula probe, hydrogen peroxide or methylene blue. Fistulogram has a limited role and MRI and endoanal ultrasound (EUS) are required in some complex cases (3).

\section{Endoanal ultrasound (EAU)}

Study by Choen et al (1991) showed that EUA is equal to manual assessment in diagnosing intersphicteric and trans sphincteric tracts but score less than manual examination in assessing primary superficial, suprasphuincteric and extrasphincteric tracts or secondary supralevator and infralevator tracts (4).

Recent studies have been more promising aided by technological improvements. Injection of hydrogen peroxide is suggested as an adjunct, which will make fistular tracts hyperechoic and thus better visualized (5). Wang et al (2014) found 3D EAU, which gave over 95\% accuracy for identification of internal opening and identification of secondary tracts, which was significantly superior to traditional manual/probe technique (6).

\section{CT Fistulogram}

CT scans, even with limitations on resolution, are much more accessible globally than MRIs. Injection of gastrografin to fistula tract with rectum filled with air to aid resolution is crucial for the success of a CT fistulogram. Even 3D films can be obtained which will greatly assist planning of surgery (7). Liang et al (2013) showed the high value of CT fistulogram in depicting perianal anatomy and delineating tracts (8). This has a limitation in being a painful and invasive procedure and somewhat inferior to MRI in imaging qualities in general, although it has a few advantages such as better visualization of gas filled abscess cavities.

\section{MRI}

Although usually reserved for certain complex fistulas due to cost and availability issues, MRI is considered the gold standard in preoperative assessment of anorectal fistula. T2 weighted sequence is the most informative. MRI allows classification of fistula according to Park's or Morris's classification, location of internal and external openings, deep abscesses, long extensions, state of anorectal wall, peri-rectal spaces as well as the damages of the internal sphincter (9). MRI can decide the response to medical therapy, risk of incontinence, procedure of choice as well as the need for referral to a specialized surgeon (10). Surgery based on MRI can reduce further recurrence by $75 \%$ (11).

\section{The spectrum of techniques}

There are many interventional surgical methods available to treat perianal fistula which has shown variable success and complications. These are measured by parameters such as time taken to heal, associated pain in between, rate of recurrence and incontinence scoring systems.

As no clearly successful method exists, surgeons select techniques depending on their experience, as well as patient and disease characteristics. It is worth examining different modalities available in some detail. It is noted that surgeons tend to use certain low success procedures as the first line due to the simplicity and low risk. In addition, to build on advantages and to negate minuses, surgeons seem to use more than one method either simultaneously or sequentially. In fact, repeated procedures, same or different, are known to bring about success at some point (12). 


\section{Fistulectomy}

This simple procedure of laying the tract open is used for low anal fistulas and found to be very effective. Even those which traverse lower third of external sphincter, can be operated with less than $10 \%$ incontinence rate (2).

\section{Seton wire}

This oldest approach, first described by Hippocrates, is noted for low risk on sphincter mechanism (13). Surgical suture or rubber strand is passed through the fistular tract and taken out via anus followed by a knot tied outside. This allows drainage over time as well as possible closure of branching tracts. Loose Seton with high recurrence rate after removal is favoured over more successful but painful tight Seton, which cuts slowly through the sphincter, leaving a trail of healing by fibrosis (13). Sometimes two Setons are used for two partial fistulotomy dividing a long tract in the middle.

Seton is considered useful to drain a tract and sometimes to convert a complex fistula to a single tract. In this role it is widely used as an adjunct to many other definitive treatment methods.

\section{Combined Partial Fistulectomy and electro- cauterization of intersphincteric tract \\ This preferred technique of the authors involves excision of distal fistular tract to external sphincter, electro cauterization of intersphincteric part and simple closure of internal opening. A $92.5 \%$ healing rate after a 19 month follow up was detected by Shafik et al in their 2014 study (14). This appears to be a simple and effective sphincter saving procedure.}

Ligation of Intersphincteric Fistula Tract (LIFT), BioLIFT and modified LIFT

LIFT involves approaching a fistula up to the interspincteric plane after identification of the internal opening via Hydrogen peroxide injection or probe. Fistula is divided and ligated with two absorbable sutures, distal tract excised and interspincteric plain drained. Preceding drainage for 6 to 12 weeks with loose Seton is advised to control sepsis and optimize the outcome.

Limura et al (2015) reports a success rate of $76.5 \%$ on a 6 month follow up (13). Based on a systematic review of 498 patients, Yassin et al (2013) reports a healing rate of $71 \%$ with a mean follow up period ranging from 4-19.5 months (15). A mean healing rate of $74.6 \%$ was recorded in a 592 patient review by Vergera-Fernandez and EspinoUrbina in 2013 (16). Study by Madbouly et al comparing successes of LIFT versus mucosal advancement flap for the treatment of intersphincteric fistula gives comparable results for healing rate, recurrence, continence and quality of life (17)

More recently, bio prosthetic grafts are used to reinforce the tied end of the retaining potion of the tract. This covers $1 \mathrm{~cm}$ in all directions from the tied end of the fistula tract and is secured in place to external sphincter with absorbable sutures to prevent migration. Han et al (2013) described a healing rate of $95 \%$ with healing time less than one month without any noteworthy postoperative complications (18). Although median operative time is about 20 minutes, bio-LIFT procedure has drawbacks in wider dissection and cost.

\section{Endorectal advancement flap (ERAF)}

A flap of rectal mucosa and part of internal sphincter with a broad vascular base is advanced to cover the internal opening without tension. Excision of infected cryptic glands improve the results. This is considered by many as the Gold standard for treatment of recurrent complex anal fistulas. Although it does not involve division of the sphincter mechanism, minor incontinence is seen in $31 \%$ and major in $12 \%(2)$.

A study by Ortiz and Marzo (2000 Dec) involving 103 patients, where Fistulectomy is combined with Endorectal advancement flap, gives $93 \%$ healing rate. Incontinence issues were seen in $8 \%$ (19).

\section{Fibrin glue}

Although initial studies appeared promising for these injections of glue with its fibroblast attracting and scaffold producing qualities, follow up studies showed decreased healing rates most probably due to the fluid nature of the material $(20,21)$. However, as the procedure is simple and minimally invasive, it could be employed at early attempts to promote healing, as approximately one third of the patients can avoid having more extensive procedures (20). Fibrin glue is an option in management of long, narrow and persistent fistular tracts (20). They also have a role in providing cover for internal opening following other procedures.

\section{Anal fistula plug (AFP)}

This lyophilized porcine derived small intestinal submucosal plug acts as a scapholding for fibroblasts facilitating tissue healing. It has been used for anorectal fistulas following its success with thoracic and abdominal wounds. After fistular tract is curetted and irrigated with Hydrogen peroxide, apex of the cone shaped plug is tied to a probe and dragged from the internal opening to external before its internal end is fixed to mucosa via a figure of eight absorbable suture. Johnson et al (2006) concluded a success rate of $87 \%$ in a comparative study with fibrin 
glue closure which scored $40 \%$ (21). However subsequent studies were disappointing and consensus conference held in 2007 decided that AFP is suitable for transsphincteric anal fistulas without any acute inflammation or infection with special attention on the technique.

In order to circumvent implant extrusion and other problems with AFP, polyglycolic acid based absorbable GORE BioA fistula plug with disk and six attached arms was developed. This can be suitably shaped to fit in to fistular tract with a disk fixed to the internal opening and covered with mucosa and arms extend along the branches of tracts. Ratto et al (2012) has reported a success rate of $72.7 \%$ out of a 11 patient study (22). No large studies are available to measure its success.

\section{Laser closure of fistula}

Drainage of abscesses and application of loose Seton precedes this novel technique. This involves closure of the internal opening with advancement flap followed by mechanical cleaning, insertion and activated withdrawal of laser emitting wire causing destruction of infected epithelium as well as shrinkage of the tract. A study by Wilhelm ( 2011) gives $81 \%$ healing rate while providing minimal trauma to the sphincter mechanism (23). Giamendo, in a similar study, gives a lesser figure of $71.4 \%$ for primary healing and conclude laser closure as safe, simple, minimally invasive and sphincter saving (24).

\section{Video assisted anal fistula treatment}

This operation involves two phases. In phase one rigid video-fistuloscope is used to identify the main tract, secondary tracts, abscess cavities and the internal opening. In phase two the instrument is used for clipping of internal opening followed by electro-cauterization of the tract on the way out. In some, an advancement flap may be used to cover internal opening. Meinero et al (2014) found 70\% healing after one year follow up of 203 patients without any incontinence (25). However this novel technique needs further studies and is suitable for only certain type of fistulas.

\section{Adipose derived stem cells (ASC)}

Multi-potent mesenchymal stem cells, derived via liposuction from adipose tissue, were injected in doses of 20-60 million cells and retained in place with fibrin glue or similar material. ASC properties of suppressing inflammation and promoting differentiation were expected to facilitate healing of the fistula. The few studies conducted so far have not shown ASC to be significantly superior to treatment with fibrin glue alone (13)(26). Further research and developments are wait for this novel technique.

\section{Management of perianal fistula in Crohn's disease}

Perianal fistulas in Crohn's disease is one of the most difficult to manage requiring multidisciplinary approach among which physicians, surgeons and radiologists play a vital role. Although medical therapy such as antibiotics, immunosuppressants, anti-TNF Alpha combined with control of sepsis by simple drainage including seton wires tend to control most of the fistulas about $25 \%$ are likely to require surgery at some stage (27). Sphincter saving minimally invasive procedures are used due to persisting cause, increasing the likelihood of recurrent operations as well as potential sphincter damage. Younger presenting age, Crohn's colitis and presence of high fistulas are markers of prolonged troublesome disease (28). Ultimate measures in management of any fistula such as proctectomy and fecal diversion may need to be employed more frequently in Crohn's associated fistula (29).

\section{Other Procedures}

Variation of techniques employed by surgeons in the management of anorectal fistula are only matched by variations in presentation. However, resistant complex fistulas leading to severe deterioration of patient's quality of life may force the hand of the surgeon and heart of the patient towards risky and drastic measures such as division and repair of the sphincter, temporary defunctioning colostomy or even an abdomino-perineal resection.

\section{Conclusion}

Search for the ideal treatment of perianal fistulas which will fulfill the objectives of low recurrence rate, minimal incontinence and good quality of life continues. Adherence to standard principals of the management of any fistula such as control of sepsis, care of nutritional status, delineation of anatomy and performing of appropriate surgical procedure (SNAP) is vital for the effective management of this troublesome disease. Wide range of procedures have been developed from simple ones such as loose seton to sphincter saving fistular plugs ending with extreme options such as temporary or permanent fecal diversion. Innovative therapeutic techniques such as the use of laser and adipose stem cells have shown some successes, but require more advancements and improvements before being accepted in to wider practice.

While simple fistulas can be managed without much difficulty, options for complex ones need careful selection. Sphincter saving options are widely preferred over risky traditional ones involving extensive dissection. Success of Ligation of intersphincteric fistular tract (LIFT) seems to stimulate development of modifications for the technique. Endorectal advancement flap (ERAF) is accepted by many as the Gold standard for treatment of recurrent complex anal fistulas. Another trend is that many surgeons 
judiciously combine different techniques employing them sequentially or simultaneously to enhance the success rate and mitigate disadvantages. Surgeons do not appear to be deterred by having to do repeated operations, provided they are sphincter saving as success can be achieved at any stage. Management of fistulas associated with Crohn's disease is a particularly complex entity requiring multidisciplinary involvement and multimodality treatment.

The field of management of perianal fistulas is wide open for further research and developments. It appears unlikely that, given the complexity of disease, a single successful method of treatment will ever be found for management of perianal fistulas.

\section{References}

1. Sheikh P. Controversies in fistula in ano. Indian $\mathbf{J}$ Surg [Internet]. 2012 Jun [cited 2018 Sep

1];74(3):217-20. Available from: http://www.ncbi.nlm.nih.gov/pubmed/23730047

2. Song KH. New techniques for treating an anal fistula. J Korean Soc Coloproctol [Internet]. 2012 Feb [cited 2018 Sep 1];28(1):7-12. Available from: http://www.ncbi.nlm.nih.gov/pubmed/22413076

3. Sileri P, Giarratano G, Franceschilli L, Limura E, Perrone F, Stazi A, et al. Ligation of the Intersphincteric Fistula Tract (LIFT): A Minimally Invasive Procedure for Complex Anal Fistula. Surg Innov [Internet]. 2014 Oct 6 [cited $2018 \mathrm{Sep}$ 1];21(5):476-80. Available from: http://www.ncbi.nlm.nih.gov/pubmed/24201738

4. Choen S, Burnett S, Bartram CI, Nicholls RJ. Comparison between anal endosonography and digital examination in the evaluation of anal fistulae. Br J Surg [Internet]. 1991 Apr 1 [cited 2018 Sep 1];78(4):445-7. Available from:

http://doi.wiley.com/10.1002/bjs.1800780418

5. Cheong DM, Nogueras JJ, Wexner SD, Jagelman DG. Anal endosonography for recurrent anal fistulas: image enhancement with hydrogen peroxide. Dis Colon Rectum [Internet]. 1993 Dec [cited 2018 Sep 1];36(12):1158-60. Available from: http://www.ncbi.nlm.nih.gov/pubmed/8253014

6. Wang Y, Ding J, Zhao K, Ye H, Zhao Y, Zhao Y, et al. [Value of three-dimensional endoanal ultrasonography for anal fistula assessment]. Zhonghua Wei Chang Wai Ke Za Zhi [Internet]. 2014 Dec [cited 2018 Sep 1];17(12):1183-6. Available from: http://www.ncbi.nlm.nih.gov/pubmed/25529948

7. Liang C, Lu Y, Zhao B, Du Y, Wang C, Jiang W. Imaging of anal fistulas: comparison of computed tomographic fistulography and magnetic resonance imaging. Korean J Radiol [Internet]. 2014 [cited 2018 Sep 1];15(6):712-23. Available from: http://www.ncbi.nlm.nih.gov/pubmed/25469082

8. Liang C, Jiang W, Zhao B, Zhang Y, Du Y, Lu Y. CT imaging with fistulography for perianal fistula: does it really help the surgeon? Clin Imaging [Internet]. 2013 Nov [cited 2018 Sep 1];37(6):1069-76.

Available from: http://www.ncbi.nlm.nih.gov/pubmed/23958432

9. Cuenod CA, de Parades V, Siauve N, Marteau P, Grataloup C, Hernigou A, et al. [MR imaging of anoperineal suppurations]. J Radiol [Internet]. 2003 Apr [cited 2018 Sep 1];84(4 Pt 2):516-28. Available from:

http://www.ncbi.nlm.nih.gov/pubmed/12844075

10. Joyce M, Veniero JC, Kiran RP. Magnetic resonance imaging in the management of anal fistula and anorectal sepsis. Clin Colon Rectal Surg [Internet]. 2008 Aug [cited 2018 Sep 1];21(3):213-9. Available from: http://www.ncbi.nlm.nih.gov/pubmed/20011419

11. Halligan S, Buchanan G. MR imaging of fistula-inano. Eur J Radiol [Internet]. 2003 Aug [cited 2018 Sep 2];47(2):98-107. Available from: http://www.ncbi.nlm.nih.gov/pubmed/12880990

12. Tyler KM, Aarons CB, Sentovich SM. Successful Sphincter-Sparing Surgery for All Anal Fistulas. Dis Colon Rectum [Internet]. 2007 Oct [cited 2018 Sep 2];50(10):1535-9. Available from: http://www.ncbi.nlm.nih.gov/pubmed/17674105

13. Limura E, Giordano P. Modern management of anal fistula. World J Gastroenterol [Internet]. 2015 Jan 7 [cited 2018 Sep 2];21(1):12-20. Available from: http://www.ncbi.nlm.nih.gov/pubmed/25574077

14. Shafik AA, El Sibai O, Shafik IA. Combined partial fistulectomy and electro-cauterization of the intersphincteric tract as a sphincter-sparing treatment of complex anal fistula: clinical and functional outcome. Tech Coloproctol [Internet]. 2014 Nov 26 [cited 2018 Sep 2];18(11):1105-11. Available from: http://www.ncbi.nlm.nih.gov/pubmed/25154751

15. Yassin NA, Hammond TM, Lunniss PJ, Phillips RKS. Ligation of the intersphincteric fistula tract in the management of anal fistula. A systematic review. Color Dis [Internet]. 2013 May [cited 2018 Sep 2];15(5):527-35. Available from: http://www.ncbi.nlm.nih.gov/pubmed/23551996

16. Vergara-Fernandez O, Espino-Urbina LA. Ligation of intersphincteric fistula tract: what is the evidence in a review? World J Gastroenterol [Internet]. 2013 Oct 28 [cited 2018 Sep 2];19(40):6805-13. Available 
from: http://www.ncbi.nlm.nih.gov/pubmed/24187455

17. Madbouly KM, El Shazly W, Abbas KS, Hussein AM. Ligation of Intersphincteric Fistula Tract Versus Mucosal Advancement Flap in Patients With High Transsphincteric Fistula-in-Ano. Dis Colon Rectum [Internet]. 2014 Oct [cited 2018 Sep 2];57(10):12028. Available from: http://www.ncbi.nlm.nih.gov/pubmed/25203377

18. Han JG, Yi BQ, Wang ZJ, Zheng Y, Cui JJ, Yu XQ, et al. Ligation of the intersphincteric fistula tract plus a bioprosthetic anal fistula plug (LIFT-Plug): a new technique for fistula-in-ano. Color Dis [Internet]. 2013 May [cited 2018 Sep 2];15(5):582-6. Available from:

http://www.ncbi.nlm.nih.gov/pubmed/23067044

19. Ortiz H, Marzo J. Endorectal flap advancement repair and fistulectomy for high trans-sphincteric and suprasphincteric fistulas. Br J Surg [Internet]. 2000 Dec [cited 2018 Sep 2];87(12):1680-3. Available from: http://www.ncbi.nlm.nih.gov/pubmed/11122184

20. Zmora O, Mizrahi N, Rotholtz N, Pikarsky AJ, Weiss EG, Nogueras JJ, et al. Fibrin glue sealing in the treatment of perineal fistulas. Dis Colon Rectum [Internet]. 2003 May [cited 2018 Sep 2];46(5):584-9. Available from: http://www.ncbi.nlm.nih.gov/pubmed/12792432

21. Johnson EK, Gaw JU, Armstrong DN. Efficacy of Anal Fistula Plug vs. Fibrin Glue in Closure of Anorectal Fistulas. Dis Colon Rectum [Internet]. 2006 Mar [cited 2018 Sep 2];49(3):371-6. Available from: http://www.ncbi.nlm.nih.gov/pubmed/16421664

22. Ratto C, Litta F, Parello A, Donisi L, Zaccone G, De Simone V. Gore Bio-A® Fistula Plug: a new sphincter-sparing procedure for complex anal fistula. Color Dis [Internet]. 2012 May [cited 2018 Sep 2];14(5):e264-9. Available from: http://www.ncbi.nlm.nih.gov/pubmed/22288601

23. Wilhelm A. A new technique for sphincterpreserving anal fistula repair using a novel radial emitting laser probe. Tech Coloproctol [Internet]. 2011 Dec 16 [cited 2018 Sep 2];15(4):445-9. Available from: http://www.ncbi.nlm.nih.gov/pubmed/21845480

24. Giamundo P, Geraci M, Tibaldi L, Valente M. Closure of fistula-in-ano with laser - FiLaCTM: an effective novel sphincter-saving procedure for complex disease. Color Dis [Internet]. $2014 \mathrm{Feb}$ [cited 2018 Sep 2];16(2):110-5. Available from: http://www.ncbi.nlm.nih.gov/pubmed/24119103

25. Meinero P, Mori L, Gasloli G. Video-Assisted Anal Fistula Treatment. Dis Colon Rectum [Internet]. 2014 Mar [cited 2018 Sep 2];57(3):354-9. Available from: http://www.ncbi.nlm.nih.gov/pubmed/24509459

26. Herreros MD, Garcia-Arranz M, Guadalajara H, DeLa-Quintana P, Garcia-Olmo D, FATT Collaborative Group. Autologous Expanded Adipose-Derived Stem Cells for the Treatment of Complex Cryptoglandular Perianal Fistulas. Dis Colon Rectum [Internet]. 2012 Jul [cited 2018 Sep 2];55(7):762-72. Available from: http://www.ncbi.nlm.nih.gov/pubmed/22706128

27. Burri E, Vavricka SR. Der anale Crohn. Ther Umschau [Internet]. 2013 Jul [cited 2018 Sep 2];70(7):417-28. Available from: http://www.ncbi.nlm.nih.gov/pubmed/23798025

28. Iesalnieks I, Glaß H, Kilger A, Ott C, Klebl F, Agha A, et al. Perianale Crohn-Fisteln. Der Chir [Internet]. 2009 Jun 24 [cited 2018 Sep 2];80(6):549-58. Available from: http://www.ncbi.nlm.nih.gov/pubmed/19387561

29. Sordo-Mejia R, Gaertner WB. Multidisciplinary and evidence-based management of fistulizing perianal Crohn's disease. World J Gastrointest Pathophysiol [Internet]. 2014 [cited 2018 Sep 2];5(3):239. Available from: http://www.wjgnet.com/21505330/full/v5/i3/239.htm 